\title{
The Iron and Manganese Content of Plants present in the Natural Vegetation of the English Lake District
}

BY

A. M. MAYER

AND

E. GORHAM

(Botany Department, University College, London)

With six Figures in the Text

\begin{abstract}
Estimations of iron and manganese have been made on ninety-six species of plants (including fungi, mosses, ferns, and flowering plants) from a wide range of natural habitats. These plants normally contain more of both elements than is usual in crop plants grown on cultivated fields, probably owing to the greater acidity and humus content of the natural soils. The amount present varies with the individual species, the plant group, and the type of habitat. While some species and groups tend to take up iron or manganese selectively, both the absolute amounts and the ratio of the two elements may vary widely without apparent injury to the plant. In general, these elements accumulate most in aquatic plants growing on organic and anaerobic muds. The lowest amounts are found in species characteristic of flushed brown earths and in plants from drained acid peats. The fruiting bodies of fungi contain little of either element.
\end{abstract}

\section{INTRODUCTION}

$\mathrm{N}$ recent years much attention has been given to the role of minor elements in plant nutrition. However, most of the work on this subject has been devoted to species of agricultural importance, growing in pots or on cultivated soils. Therefore, when an opportunity arose of obtaining vegetation from a wide range of natural habitats, it was felt that analyses for certain of the minor elements might be worth while both intrinsically and for comparison with the data available on crop plants.

Iron and manganese were chosen for study as being likely to show marked differences in amount according to the habitats in which the plants grow. Uptake of these two elements is presumably related, at least in part, to the concentration of soluble forms in the external medium. Thus it might be expected that the availability of iron and manganese would be conditioned by three factors which may vary widely in the soil:

(I) hydrogen-ion concentration,

(2) redox potential,

(3) organic content.

[Anals of Botany, N.S. Vol. XV, No. 88, Aprll 1951.] 


\section{$248^{\prime}$ Mayer and Gorham-Iron and Manganese Content of Plants}

It is well known that the solubility of iron and manganese compounds generally rises with increasing acidity. Also, anaerobic conditions in the soil have been shown to bring about the reduction of ferric ions and compounds to ferrous forms (Pearsall, 1938; Misra, 1938; Mortimer, 194I). That these are more mobile and able to enter the soil-exchange complex has been demonstrated by Ignatieff (194I) and Gorham (1949). In the presence of organic matter a variety of complex iron humates may be formed. McMurtrey and Robinson (1938) claim that these may remain stable and soluble in conditions of acidity and oxidation at which the element in its ionic state would precipitate as ferric hydroxide. As an example of the influence of organic compounds we may cite the work of Hopkins and Wann (1926), who showed that iron remains available to the alga Chlorella in culture solutions at $\mathrm{pH} 6$ only if citrate is added to the medium to prevent its precipitation. In contrast, Bremner et al. (1946) suggest the presence in soils of polyvalent metallo-organic complexes' which appear to be non-exchangeable and insoluble in water. These compounds are, however, broken down by organic ions such as citrate and malate, which are known to form co-ordination complexes with polyvalent metals. In all these examples it is probable that manganese and iron may behave in similar fashion.

Another possible influence on the uptake of these elements has been suggested by Olsen (1934). He believes that the concentrations of other elements in the soil may strongly affect manganese uptake. From what is known of mineral metabolism in general, this seems highly probable.

From the above it would seem that a clear correlation of iron or manganese uptake with any one soil factor is rather unlikely. And in fact it is impossible at present to attempt the explanation of many of the results of this survey. Their interpretation must await further knowledge of the chemistry of iron and manganese in the soil as well as of their physiological role in plants.

\section{DA T A}

The samples were all collected in the southern part of the Lake District, an area of marked relief and high rainfall. The soils are mostly glacial loams and clays deposited over Silurian slates and grits, but plants have also been taken from the occasional limestone outcrops. The habitats sampled may be classed as follows:

\section{Woodland soils}

Calcareous, neutral, and seldom highly organic.

Slightly acid flushed brown earths having a mull type of humus mixed with the mineral horizons.

Highly leached podzolic soils, with an acid mor humus tending to accumulate on the surface.

\section{Waterlogged soils}

Underwater soils, usually slightly acid, anaerobic, and strongly reducing at rooting levels (Misra, 1938). Ignition loss less than 30 per cent. 
Semi-aquatic, ranging from inorganic (silted) marsh soils to highly organic fen and lacustrine peats. Generally moderately reducing, but sometimes oxidized during the summer (Pearsall, 1938), and exhibiting a considerable range of acidity.

Raised bog peats, formed in regions of high humidity by the growth of the bog moss (Sphagnum), on waterlogged sites once the level of peat deposition has risen above the influence of ground water. The bogs considered here have all ceased to grow in size or extent, and have been much cut and drained. Drainage has resulted in oxidation of the surface peat, which accounts for its high acidity (Pearsall, 1938a). However, reducing conditions probably obtain during much of the growing season, as the peats are still very wet. A further consequence of drainage is the change from Sphagnum to Calluna vulgaris and Eriophorum vaginatum as the dominant species.

It should be emphasized that there is a good deal of intergradation in this classification.

\section{METHODS}

Sampling. The plants and the soils in which they were rooted were collected during June, July, and August of 1948 and 1949 , an effort being made to sample individuals of the same group of plants at the same time. The woodland trees were all taken in the seedling state.

Leaves were taken except in the case of the fungi, of which the fruiting tops were selected, and the mosses and grassy plants, where the green tops were sampled. All leaves on the plants were collected. The analyses therefore give results for the chief photosynthetic organs, except for the fungi. Only fresh healthy tissues were sampled, from normal plants growing in what appeared (with one or two exceptions as noted) to be their natural habitats. While fresh they were carefully washed with water to exclude surface contamination as far as possible. Afterwards they were placed in a drying-room and stored when air-dry. Three hundred to one thousand milligrams of material were normally used for analysis, but in a few cases of usually solitary species such as Solidago as little as $50 \mathrm{mg}$. were used.

Drying and ashing. Both soils and plants were dried at $100^{\circ} \mathrm{C}$. to constant weight and ashed at about $55^{\circ} \mathrm{C}$.

Preparation of plant ash for analysis. The ash was extracted with $2 \mathrm{ml}$. of concentrated hydrochloric acid at $60-70^{\circ} \mathrm{C}$. The extract was then diluted to $50 \mathrm{ml}$. with distilled water and divided into two parts for subsequent analysis.

Iron estimation. I ml. of $3 \mathrm{~N}$ potassium thiocyanate was added to the above extract. The red colour obtained was then compared in a visual colorimeter with a standard iron solution, prepared from reduced iron dissolved in concentrated hydrochloric acid and diluted as required.

Manganese estimation. I $\mathrm{ml}$. of phosphoric acid was added to the prepared extract, followed by $0.5^{-1} \cdot \mathrm{og}$. of potassium periodate. The solution was then boiled for 3 minutes, allowed to cool, and made up again to standard volume. 


\section{Mayer and Gorham-Iron and Manganese Content of Plants}

Care had to be taken that the periodate was present in excess, so that the solu-. tion did not fade on cooling. Comparison, using a standard prepared from potassium permanganate, was again carried out in the visual colorimeter, phosphoric acid and potassium periodate being added to prevent decomposition during the matching.

$p H$ of the soil. For this determination a glass electrode was used on undiluted soil which had been stored at low temperature in specimen tubes without drying. Tests on fresh and stored soils indicated that the changes on storage were within the normal range of variation for individual samples from the same site during the summer.

While errors are liable to arise from the rather small size of the samples, with consequent difficulty in obtaining homogeneity, the results suggest that these errors lie well within the normal range of variation of the individual species. It is not possible to say how far the results are affected by variation in the age of the plants when collected, or by the differences in the parts sampled from groups such as grass and herbs.

In the presentation of the data, ash is shown as per cent. of dry weight, manganese and iron are given as milligrams per hundred grammes of dry matter (throughout the text referred to simply as milligrams). Soil ignition loss is given as per cent. dry weight.

\section{RESULTS}

The analytical results for the individual species are presented in Tables I to $\mathrm{IX}$, in each of which the results are arranged in order of soil $\mathrm{pH}$ and with the organic content of the soil added for reference. The tables group the species under the general headings of (I) woodland plants and (II) plants from wet soils. For the woodland species, it has been found convenient to sort out various groups of plants for separate consideration. The plants of wet soils have been grouped differently, according to the three main habitat types. Attention is drawn below to certain features of general interest.

\section{Woodland plants}

Mosses (Table I). This group of plants shows a striking tendency to accumulate iron, the highest figure being $400 \mathrm{mg}$. Over half the iron values are above the maximum recorded for manganese, which is $77 \mathrm{mg}$. for a sample of Plagiothecium elegans from a conifer wood.

These mosses are representative of three types of habitat. The first three species in Table I were sampled from crevices in impure Coniston limestone and show a high iron content. The next five were on leached mineral soil and show the lowest values for iron among the three groups. The last three specimens were growing on organic mor humus accumulations and these also show a high iron uptake, though less than that of the first group. Dicranum majus, which was sampled on all three habitats, shows the same picture as the group results. It would appear from this that the impure limestones and the mor humus contain relatively more available iron than the leached mineral 


\section{TABLE I}

Mosses

Species.

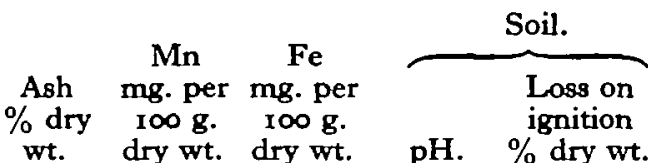

Trichostomum tortuosum

Hypmum molluscum

Dicranum majus*.

Catharinea undulata . . . $\quad 3 \cdot 1$

Plagiothecium elegans . . . . 6.

Mrium hornum

$5 \cdot 7$

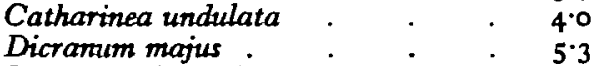

Hyprum schreberi

Leucobryrm glaucum $\quad . \quad$. $\quad 2.8$

Dicranum majus.

- From atypical habitat.

soil. Much of the available iron in the last soil has presumably been leached from the surface and is therefore beyond reach of the mosses.

It is of some interest that the two calcicole species, Trichostomum tortuosum and Hypnum molluscum, have the highest amounts of ash and iron and are also relatively high in manganese.

Ferns (Table II). Among these plants, in contrast to the mosses, there appears to be no selective accumulation of either element to any great extent. The upper level for iron is $53 \mathrm{mg}$. and the manganése content is usually below $42 \mathrm{mg}$.

\section{TABLE II}

\section{Ferns}

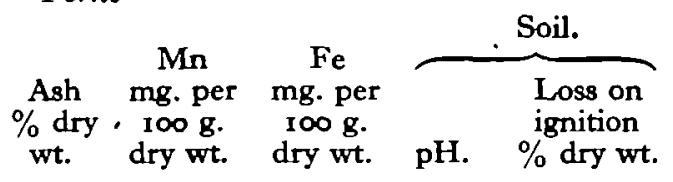

Phyllitis scolopendrium.

Species.

$\%$ dry $100 \mathrm{~g} . \quad 100 \mathrm{~g}$.
wt. dry wt. dry wt.

Dymocarpium robertianum . $\quad 8 \cdot 8$

Dryopteris flix-mas . . . 9.4

Athyrium filix-femina . . . 114

Pteridium aquilinum . . . $7 \cdot 7$

Gymnocarpium dryopteris . . 9.1

Blechrum spicant. . . . 8.3

Thelypteris phegopteris . . . $\quad 8.9$

Dryopteris spinulosa . . . . 7.3

Pol" filix-mas . . . 5.9

Polypadium vulgare $\cdot \quad \cdot \quad \cdot 3.6$

18
20
13
9
33
26
29
20
140
12
21
42

20
20
39
47
26
35
16
53
21
23
40
26

$7 \cdot 05$

$6 \cdot 70$

$5 \cdot 45$

$5 \cdot 43$

4.76

4.73

$4 \cdot 58$

$4 \cdot 52$

$4 \cdot 10$

3.67

$2 \cdot 88$

$2 \cdot 48$

-
18
9
14
12
18
12
19
50
80
68

A single exception is the case of Dryopteris spinulosa, one specimen of which contained $140 \mathrm{mg}$. of manganese. This was the only fern collected from a 


\section{Mayer and Gorham-Iron and Manganese Content of Plants}

conifer wood and may be compared with Plagiothecium elegans, which had the highest level of manganese among the mosses.

Grasses (Table III). Of the grasses selected for analysis most attention has been given to three species characteristic of different soil types. Brachypodium sylvaticum is a species of flushed brown earths, Holcus mollis is most frequently found on moderately leached soils, and Deschampsia flexuosa is one of the dominant plants on the most acid and heavily leached podzolic soils.

\section{TABLE III}

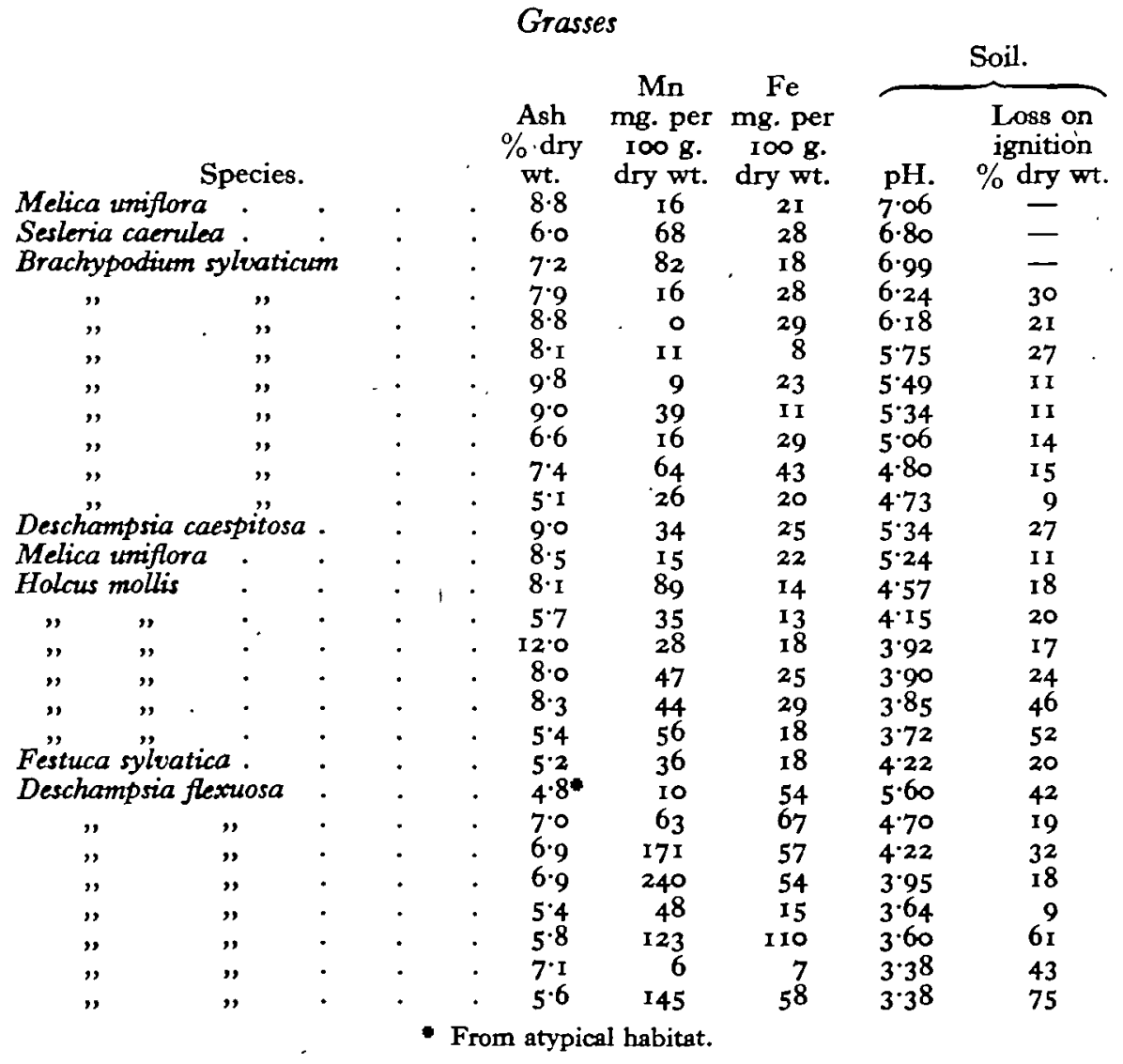

Deschampsia flexuosa shows the greatest uptake of both elements. The upper limit of manganese in this species is $240 \mathrm{mg}$, and of iron $110 \mathrm{mg}$. Holcus generally exceeds Brachypodium in manganese, ranging from 28 to 89 as compared with o to $82 \mathrm{mg}$.; while iron is roughly similar in both species and is always below $44 \mathrm{mg}$.

Although Deschampsia flexuosa usually contains fairly large amounts of both elements, it appears able to grow normally with relatively low levels of iron and manganese in its tissues. For example, one collection, from an abundant 
growth on an acid leached soil with a grey $A_{2}$ horizon, contained only $6 \mathrm{mg}$. of manganese and $7 \mathrm{mg}$. of iron per hundred grammes dry weight. This suggests that most of the available soil reserve of the two elements had been leached beyond reach of the grass roots.

Herbs (Table IV). Here again three species have been given special attention. Mercurialis perennis is perhaps the most characteristic plant of the flushed habitats, while Digitalis purpurea and Solidago virgaurea grow over the whole range of woodland soils. The results, however, are not very informative.

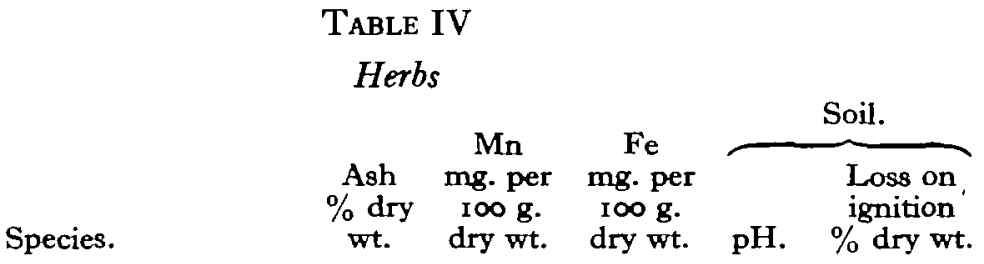

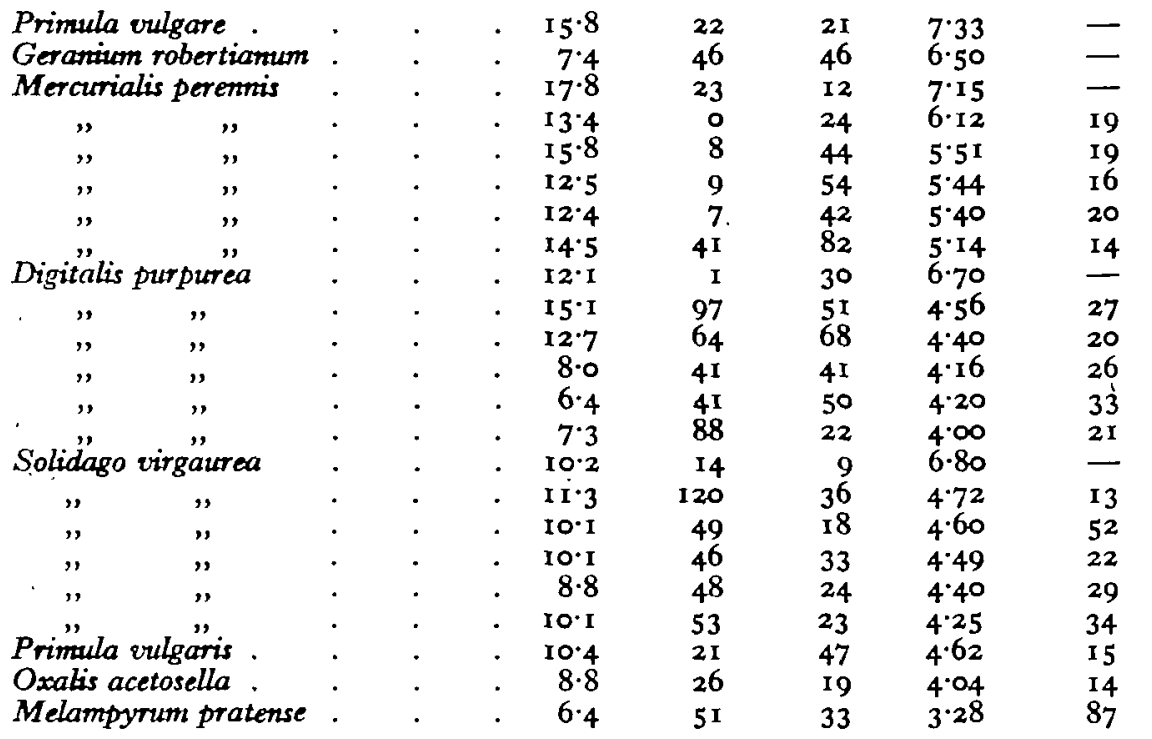

There is no strong accumulation of either element, manganese being always below $121 \mathrm{mg}$. and iron less than $82 \mathrm{mg}$. Of the various plant groups studied, herbs have the greatest mineral intake as shown by ash content. It would appear, then, that iron and manganese in this group form a relatively less important proportion of the total mineral consumption than in any other green plants.

In five out of six cases Mercurialis has more iron than manganese, the latter being always under $42 \mathrm{mg}$. and generally less than in the other two species. In all six samples of Solidago, on the other hand, manganese exceeds iron.

Woody plants (Table V). The most evident feature of this group of plants is the high level of manganese in most species, coupled with very low figures 
for iron. Manganese ranges up to $386 \mathrm{mg}$., and seven samples exceed $100 \mathrm{mg}$., while iron never rises above $43 \mathrm{mg}$.

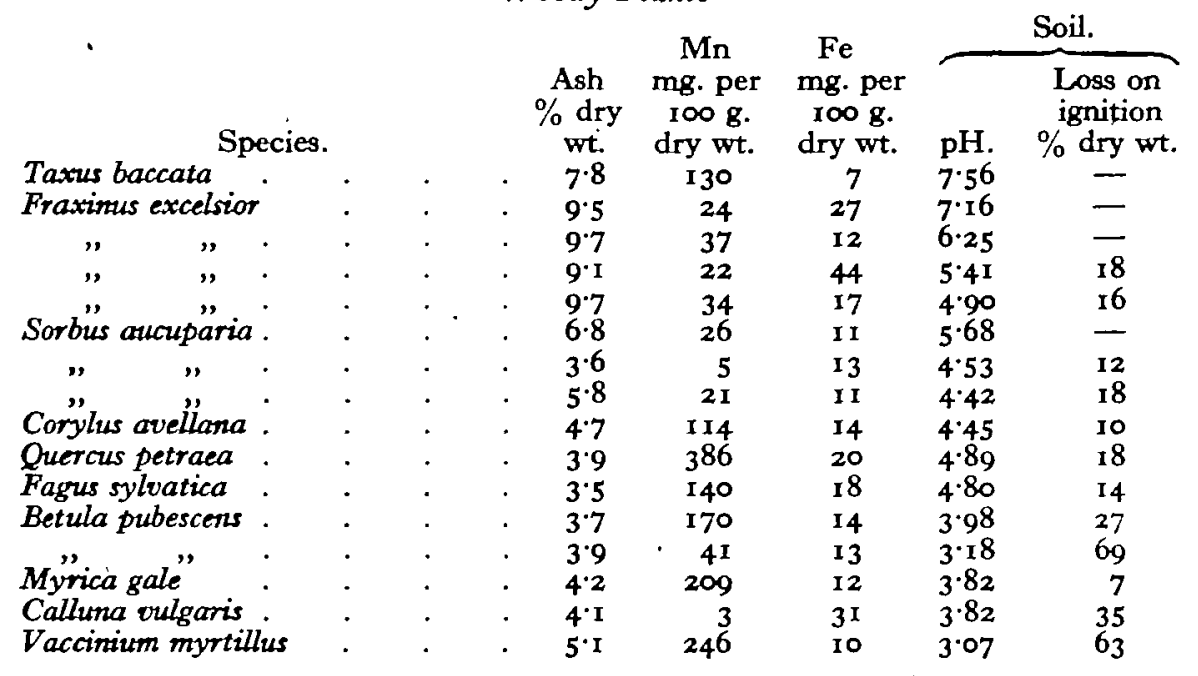

TABLE V

Woody Plants

Fraxinus, the most typical tree on the flushed soils, has a relatively low manganese content. Strangely enough, the same is true of Sorbus aucuparia, which usually accompanies oak on the acid soils.

It may be pointed out that these results contrast with those of McHargue and Roy (1932), who found only 3 of 23 species of trees accumulated manganese in excess of iron. All of their species, however, were growing on soils derived from limestone.

\section{TABLE VI \\ Fungi}

Species.

On flushed brown earths

Amanita rubescens

Russula cyanoxantha

Paxillus convolutus

Cantherella cibarius

Russula adusta

Boletus nigricans

On leached podzolic soils

Amanita mappa .

", muscaria

Lactarius quietus .

Russula nigricans .

Hypholoma fasciculare

$\begin{array}{ccc} & \text { Mn } & \text { Fe } \\ \text { Ash } & \text { mg. per } & \text { mg. per } \\ \% \text { dry } & \text { I00 g. } & \text { I00 g. } \\ \text { wt. } & \text { dry wt. } & \text { dry wt. }\end{array}$

$12 \cdot 8$

$<2$

I I 0

9.4

$8 \cdot 8$

$7 \cdot 6$

$7 \cdot 2$

$7 \cdot 2$

$\begin{array}{rr}<2 & 11 \\ 2 & 6 \\ 3 & 12 \\ 2 & 9 \\ <1 & 8 \\ 1 & 5 \\ <1 & 5\end{array}$

10.7

9.5

$9 \cdot 0$

$7 \cdot 8$

$\begin{array}{rr}<4 & 12 \\ 3 & 9 \\ <2 & 14 \\ 1 & 5 \\ 5 & 29\end{array}$


Fungi (Table VI). Samples of fungi were collected because it was thought that a group which does not photosynthesize might furnish an interesting comparison with the green plants. Unfortunately clear hyphae could not be obtained pure and in quantity, so that fruiting tops had to be used. For this reason the results may not be strictly comparable.

On this basis, while the ash content is fairly high the upper limits of intake of iron and manganese are remarkably low in comparison with green plants, being $29 \mathrm{mg}$. for the former and $5 \mathrm{mg}$. for the latter. In every case iron exceeds manganese. There is perhaps a very slight tendency towards a higher uptake on the leached soils.

\section{Plants from wet soils}

Aquatic plants (Table VII). Among the plants on wet soils this group takes up the greatest amounts of both iron and manganese, and also shows the highest total mineral uptake, as may be seen from the high ash content of the species. There is, however, a great deal of variability in both elements and no definite trend towards selective absorption of either by the group as a whole.

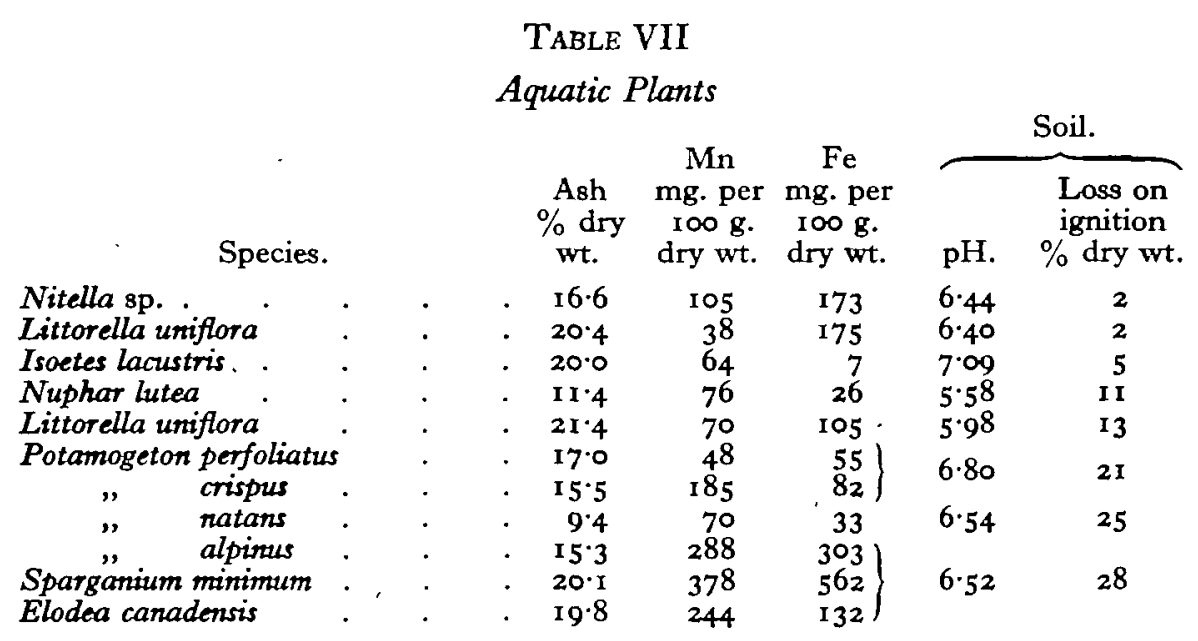

The highest figures are those for Sparganium minimum and Potamogeton alpinus, species characteristic of the most organic lake muds. The former contains $378 \mathrm{mg}$. of manganese and $562 \mathrm{mg}$. of iron, while the latter has 288 and $303 \mathrm{mg}$. respectively. It is on these sites, rich in reduced and soluble iron and manganese, that one might expect both elements to be most easily available to plants.

It is perhaps possible that some of the iron and manganese is precipitated on the leaves of these underwater plants, although this could not be observed. Since only normal healthy leaves were selected, such precipitation if it did occur would no doubt be of much physiological importance.

Mosses from semi-aquatic soils (Table VIII $a$ ). It is again very noticeable that 


\section{Mayer and Gorham-Iron and Manganese Content of Plants}

in wet soils as in woodland, mosses assimilate much more iron than manganese. In the present case the content of iron is at least twice that of manganese in most instances. The upper limits are $307 \mathrm{mg}$. of iron and I7I mg. of manganese, both figures referring to a specimen of Hypnum cordifolium from the drift zone of a fen. Sphagnum plumulosum contains the smallest amount of iron and is also low in manganese.

\section{TABLE VIII $a$}

\section{Mosses from Semi-aquatic Soils}

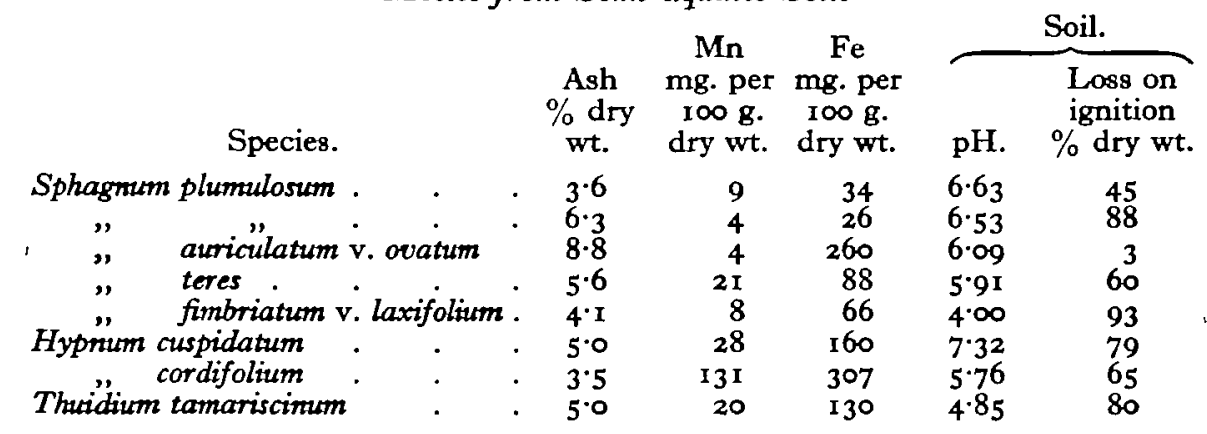

\section{TABLE VIII $b$}

Other Plants on Semi-aquatic Soils

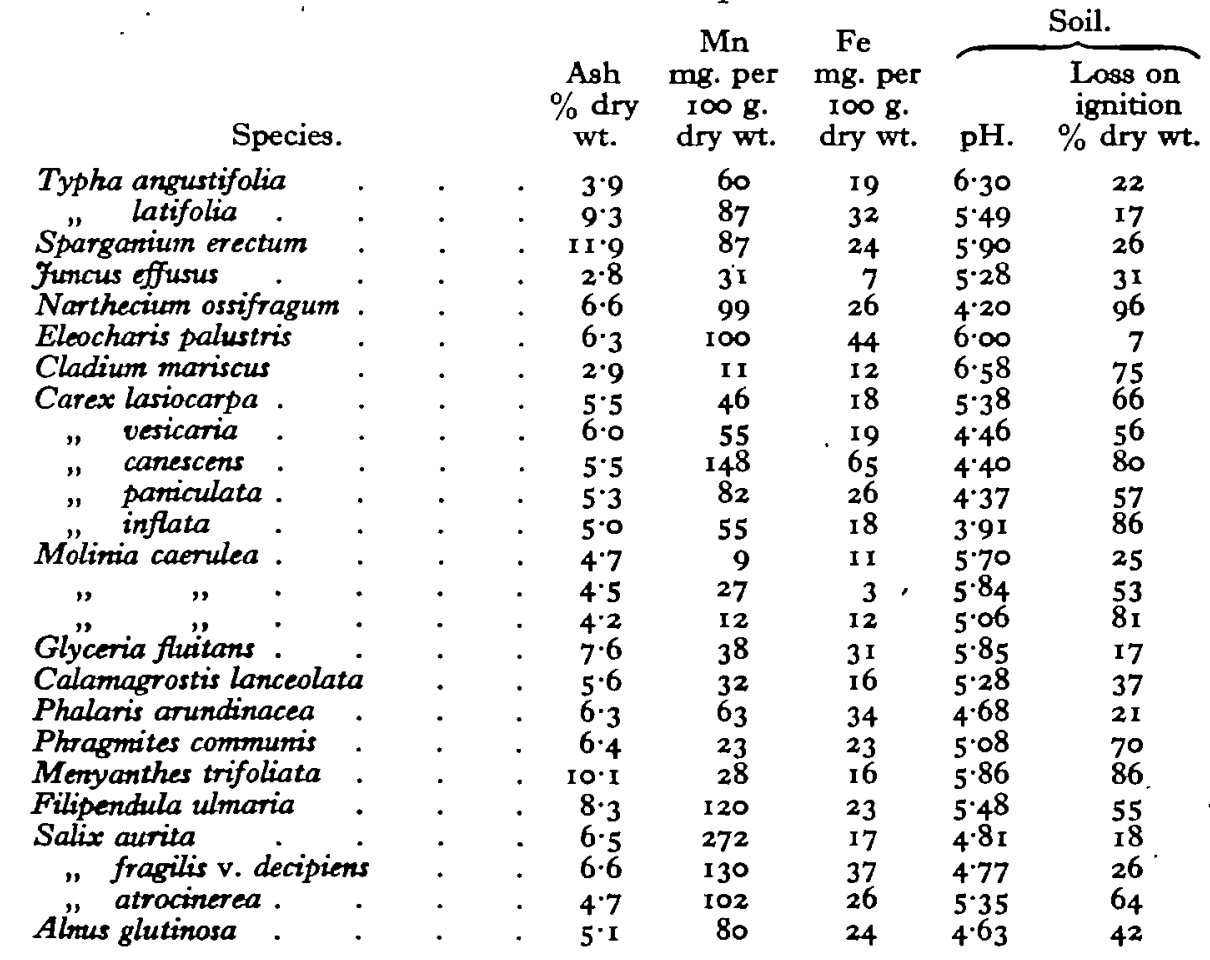




\section{present in the Natural Vegetation of the English Lake District}

Other plants from semi-aquatic soils (Table VIIIb). On these soils, which range from neutrality to $\mathrm{pH} 4$ and from silt to peat, manganese uptake by plants other than mosses reaches far greater heights than does that of iron. The top values are $272 \mathrm{mg}$. of the former and $65 \mathrm{mg}$. of the latter. There is little correlation of accumulation with $\mathrm{pH}$ or organic content of the soil.

Trees are rather high in manganese, having from 80 to $272 \mathrm{mg}$. Grasses appear to be relatively low, with from 9 to $63 \mathrm{mg}$.

Raised-bog plants (Table IX). On these sites the species sampled (which unfortunately do not include any mosses) all absorb more manganese than iron. Figures run from 35 to $50 \mathrm{mg}$. of the former and from 10 to $21 \mathrm{mg}$. of the latter. Accumulation by the plants on these oxidized peats is rather low in comparison with plants on the other wet soils, as is the total mineral intake measured by ash content.

\section{TABLE IX}

\section{Plants from Oxidized Raised-bog Peats}

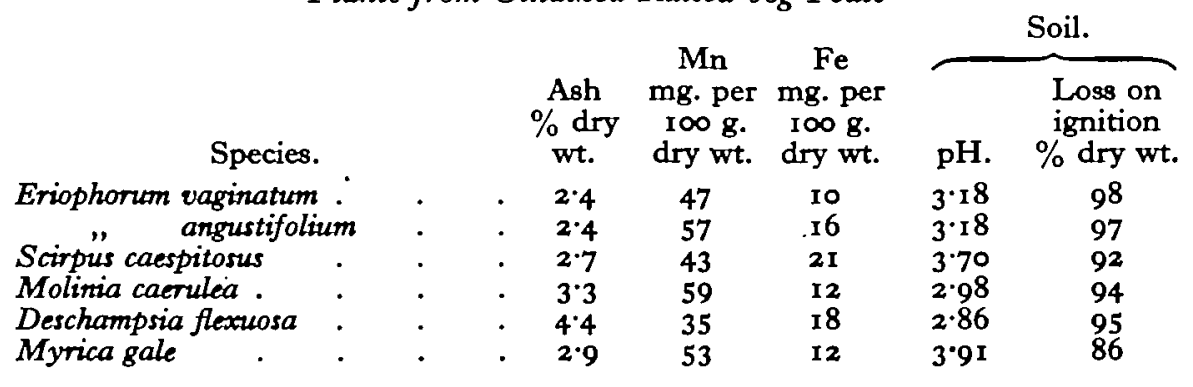

\section{Discussion}

One of the notable features of this investigation is the high proportion of both iron and manganese present in natural vegetation. The values for manganese are much greater than those recorded by Goodall and Gregory (1947) for crop plants. The reasons for this are possibly to be found in the differences in natural and cultivated soils. The former are generally more acid, and compounds of iron and manganese are usually more soluble at higher hydrogen-ion concentrations. Natural soils also tend to contain more humus and therefore have a greater adsorptive capacity. Both elements may be adsorbed on the humus colloids and thus prevented from precipitating as ferric hydroxide or manganese dioxide. In addition the probable formation of stable and soluble organic complexes should not be overlooked.

No close correlation of accumulation of either element with soil $\mathrm{pH}$ could be observed in those plants of which several samples were collected. This is contrary to the findings of Olsen (1934), who obtained a good correlation of manganese in individual woodland species with the $\mathrm{pH}$ of the soil in which they were growing. It seems likely that the high degree of relief and marked variability in microtopography of the Lake District woodlands might lead to large differences in local leaching intensity and therefore in the concentration 


\section{$25^{8}$ Mayer and Gorham-Iron and Manganese Content of Plants}

of the elements in the soil. In this connexion we may note that the Danish sites do not show the extremes of acidity found in the Lake District. In the latter locality, then, the absolute amount of available minerals may vary more and therefore play a larger part in determining plant absorption. That manganese assimilation is much greater at higher concentrations has been clearly shown by Olsen in the laboratory. It is probably generally true of iron also. For example, a green alga (Chlorella vulgaris) shows a direct correlation of iron content with supply of this element in the culture medium, as may be seen from Table X.

\section{TABLE X}

Relation of Iron Uptake by Chlorella vulgaris to Iron Supply in the Culture Solution

\begin{tabular}{|c|c|c|}
\hline $\begin{array}{c}F e \\
\text { supplied } \\
\text { p.p.m. }\end{array}$ & $\begin{array}{l}\text { Ash } \\
\% \text { dry wt. }\end{array}$ & $\begin{array}{l}\text { Uptake, } \mathrm{Fe} \\
\text { mg. per } \\
100 \mathrm{~g} . \\
\text { dry wt. }\end{array}$ \\
\hline 0.05 to 0.10 & $\left\{\begin{array}{l}4 \cdot 7 \\
5 \cdot 8 \\
6 \cdot 3\end{array}\right.$ & $\begin{array}{l}5 \\
4 \\
6\end{array}$ \\
\hline 0.10 to 0.50 & $\left\{\begin{array}{l}4 \cdot 2 \\
5 \cdot 6 \\
6 \cdot 1\end{array}\right.$ & $\begin{array}{l}21 \\
22 \\
2 I\end{array}$ \\
\hline 1.0 & $\left\{\begin{array}{l}5.0 \\
6.6\end{array}\right.$ & $\begin{array}{l}45 \\
45\end{array}$ \\
\hline
\end{tabular}

It is interesting to observe that marked accumulation of manganese by the Danish plants begins below about $\mathrm{pH}$ 5. This value was determined colorimetrically and corresponds to a lower figure, possibly about $\mathrm{pH} 4.7$, using a glass electrode and the sampling methods employed by us. The latter figure lies on the borderline between flushed soils with mull humus and leached soils with mor humus in the Lake District.

It should be of great interest to determine whether there are any differences in the uptake of iron or manganese by plants in general on the brown earths and the leached podzolic soils. In order to compare series of such variable results a derivative of the frequency curve has been employed. The method consists in plotting, for a number of levels of the element considered, the percentage of the total number of samples whose content lies on and below each given level. In this way we may obtain a summation curve, generally sigmoid in form, which gradually approaches 100 per cent. as the maximum level of the element is increased. For example, 60 per cent. of the green plants sampled contain less than $30 \mathrm{mg}$. of iron per hundred grammes dry weight, while 76 per cent. have less than $5^{\circ}$ and 96 per cent. less than $180 \mathrm{mg}$. If one curve lies below another at a given level of the element it is evidence of a higher percentage of samples with a content above that level. Again in illustration, 60 per cent. of all green plants sampled have less than $30 \mathrm{mg}$. of iron, while $4 \mathrm{I}$ per cent. have less than $30 \mathrm{mg}$. of manganese. Conversely, only 
$4^{\circ}$ per cent. of the green plants have more than $30 \mathrm{mg}$. of iron, while 59 per cent. have more than $30 \mathrm{mg}$. of manganese. An examination of Fig. 2, plotted in this way, shows that manganese in plants from leached soils exceeds that in plants from flushed soils.

In the present instance all green plants which were growing on woodland soils of $\mathrm{pH}$ less than 4.5 were taken as representative of uptake on the leached soils; those on soils above $\mathrm{pH} 5.0$ were considered to be typical of accumulation on the flushed soils. The data are weighted unequally in that where

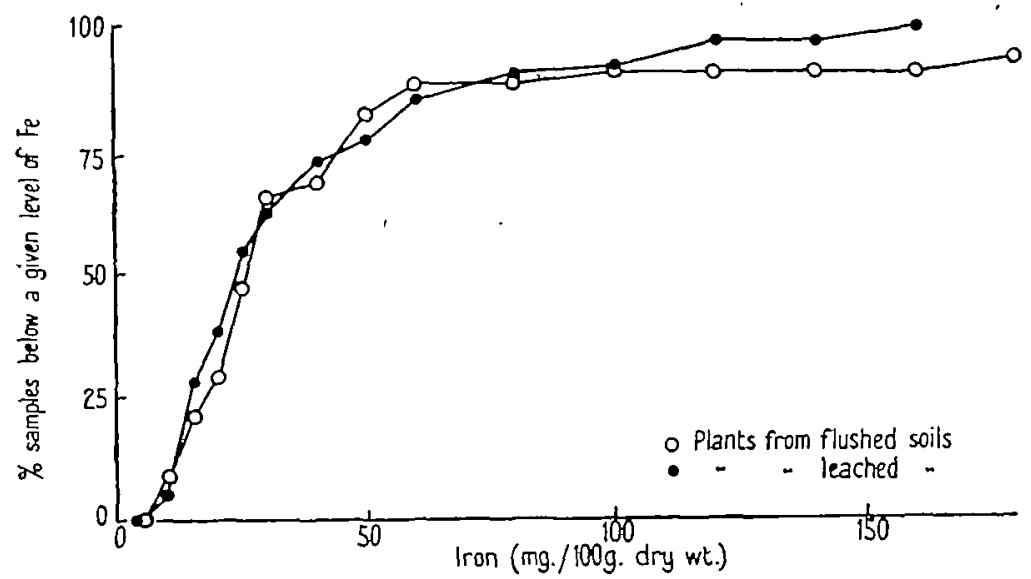

Fig. I. Iron in green plants from flushed and leached soils.

several samples of a species were collected all are included, as an average value of such variable results would be meaningless. Nor are the numbers of species from the different plant groups equal on the two soil types. Finally, an accurate assessment of the specific composition of plant communities on the two habitats is lacking. For these reasons the results should be taken as merely suggestive of certain relationships, and not in any way conclusive.

In Fig. $I$ is shown the uptake of iron by green plants on the two woodland soil types. In Fig. 2 the results for manganese are presented. With the above limitations in mind, the curves suggest that for the plants considered iron uptake is much the same on the two soils, whereas the accumulation of manganese is far greater on the leached than on the flushed habitats.

By inspection of the figures it may also be seen that on the leached soils the content of manganese in the plants examined greatly exceeds that of iron. On the flushed series the reverse is true, though there is little significance in the difference between the two elements.

These results are somewhat similar to those of Olsen's (1934) for beech leaves. He found little difference in the iron content of leaves from trees on acid and neutral sites, while manganese varied greatly. On the neutral soils the quantity of manganese in the leaves was usually slightly less than that of iron; whereas on acid soils manganese was much in excess of iron. Erkama 
260 Mayer and Gorham-Iron and Manganese Content of Plants

(I947) found plants from acid woodland to contain more manganese than iron, while garden plants on alkaline soils assimilated iron in excess of manganese.

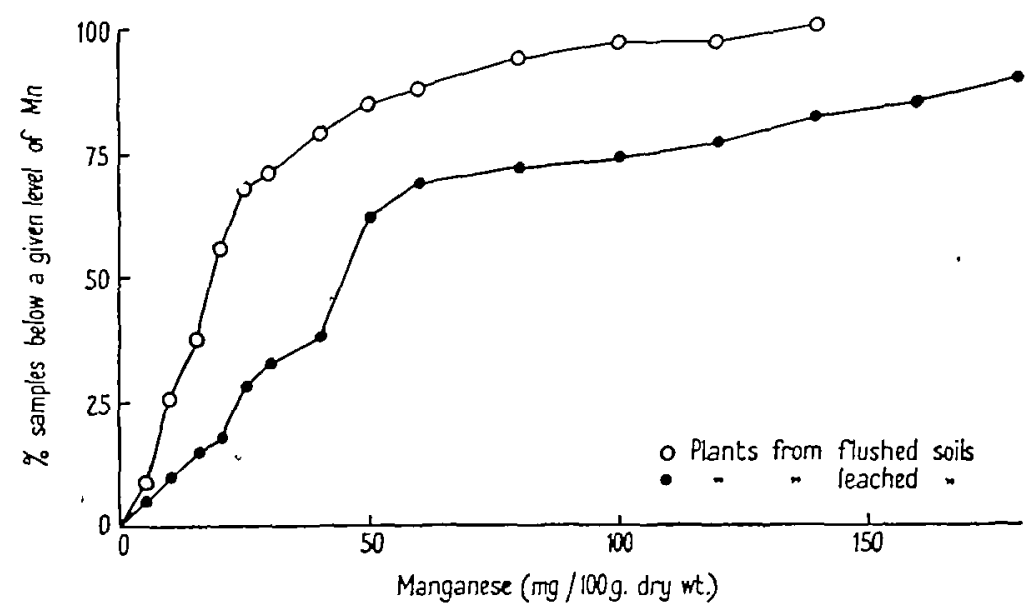

Fig. 2. Manganese in green plants. From flushed and leached soils.

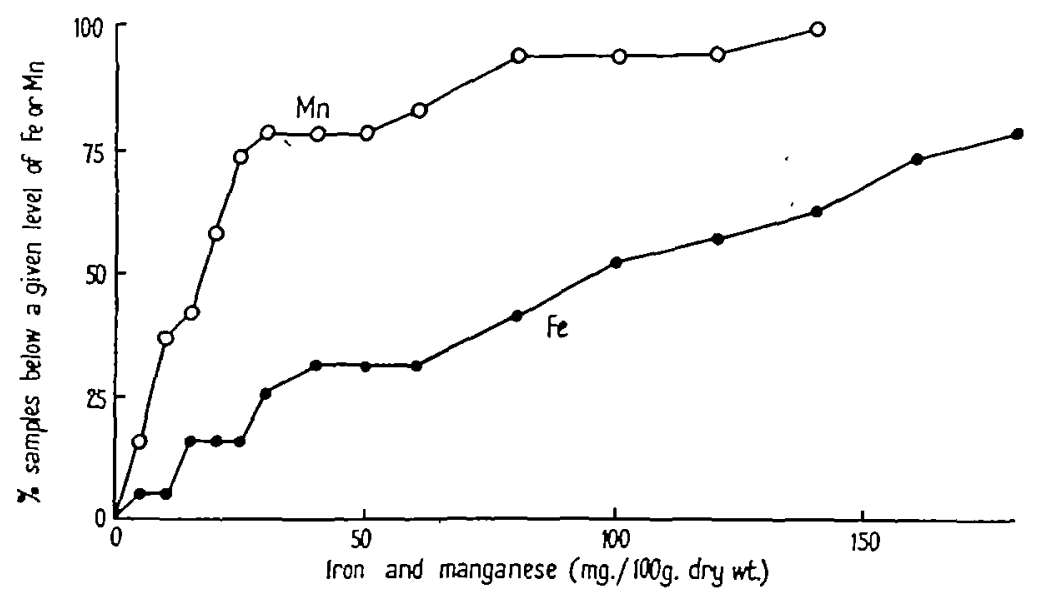

FIG. 3. Uptake of manganese and iron by mosses.

Where supplies are readily available the amounts of iron or manganese taken up depend on the plant. For example, mosses accumulate iron in large quantities, while trees on the same soils appear to absorb manganese in preference to iron. This is very clearly shown in Figs. 3 and 4. It is interesting that on the soils investigated here fungi and mosses, the simplest plants studied, appear to absorb iron selectively, while the general trend among the 'higher' plants is in the reverse direction, though perhaps not so strongly marked. In this connexion it may be noted that a single lycopod species from 
Scottish limestone, Selaginella selaginoides, also showed a great accumulation of iron, $550 \mathrm{mg}$. as against $33 \mathrm{mg}$. of manganese. The only plants found to take up both elements in large amounts were certain of those on the strongly reducing lake muds.

On the other hand, most species can probably grow normally with far less than their usual intake of these micro-nutrients. As an illustration we may again consider Deschampsia flexuosa. This species can accumulate well over $100 \mathrm{mg}$. of manganese. However, an abundance of healthy plants on a heavily

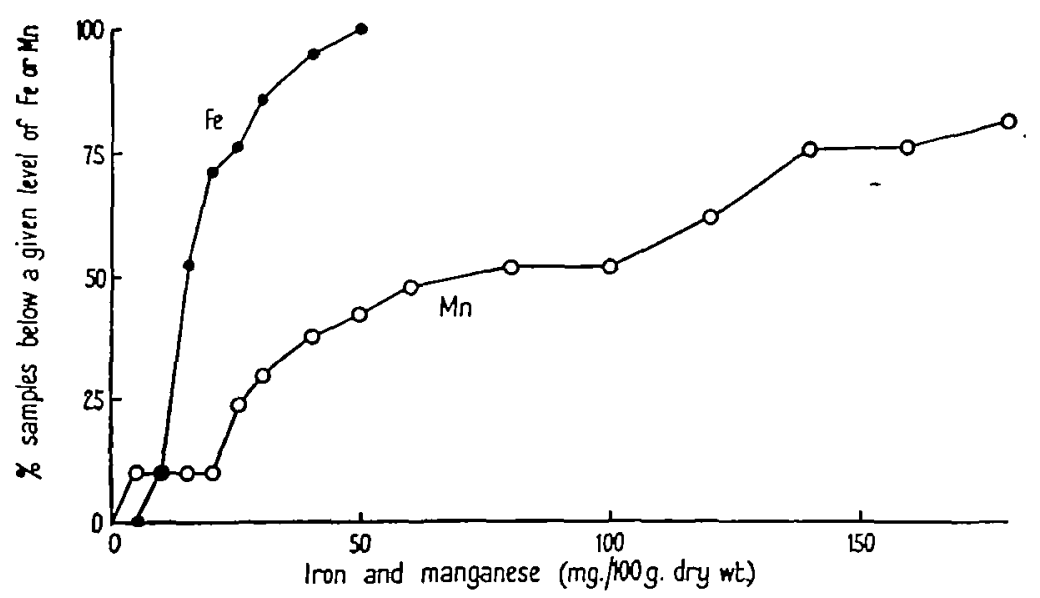

Fic. 4. Uptake of manganese and iron by woody plants.

leached knoll contained only $6 \mathrm{mg}$. of this element. A similar picture is given with regard to iron by the moss Dicranum majus. It is not clear whether the characteristic high contents of iron or manganese in some species are due to a selective metabolic process or to accumulation because mechanisms to exclude them are lacking. They appear at any rate to be something of a luxury consumption. The sis-all amounts of both elements in the fungi may suggest that there is a possible connexion between photosynthesis and the absorption of iron and manganese in large quantities.

Certain workers have stated that the ratio of iron to manganese may be of great importance (Somers and Shive, I942). However, this claim is based on the determination of active iron and manganese, which is an empirical concept whose value is not clearly established. The fact that plants on acid soils accumulate manganese rather than iron, while on circumneutral soils the reverse is more likely, might be taken to support the idea of ratio importance, but may equally possibly reflect soil availability. In contrast the fact that mosses selectively absorb iron and trees manganese probably indicates a real metabolic peculiarity. In spite of these considerations, a perusal of the data for species of which several samples have been taken shows a wide variation both in the amounts absorbed and in the ratio, without apparent effect on the health or abundance of the plants. It is probably true to say that while certain species 


\section{2}

Mayer and Gorham-Iron and Manganese Content of Plants

tend to absorb more of one element than the other, both the absolute amounts and the ratio of one to the other may apparently vary a good deal without harm to most plants.

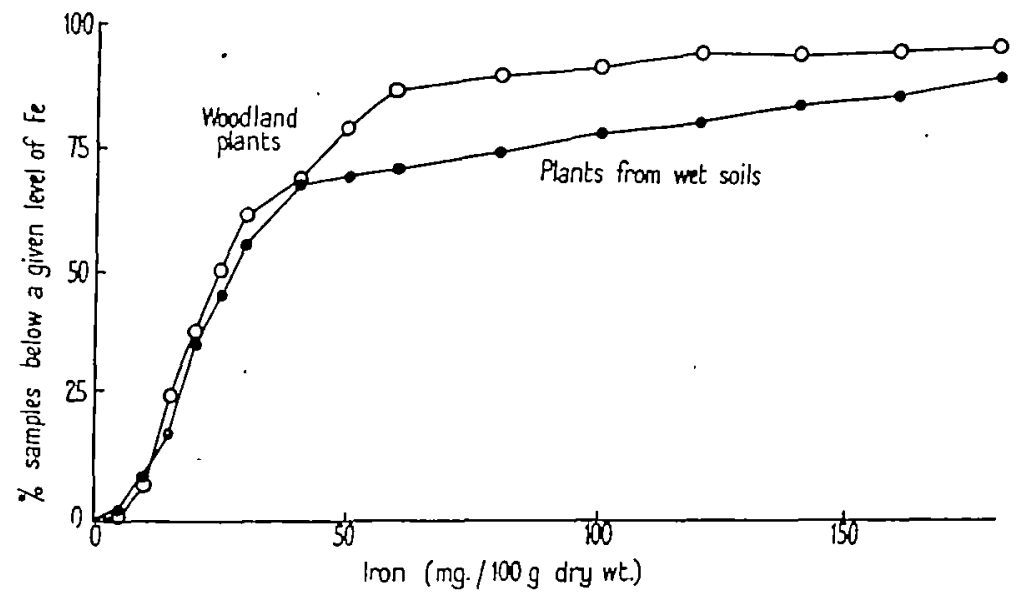

FIG. 5. Iron in green plants from woodland and waterlogged soils.

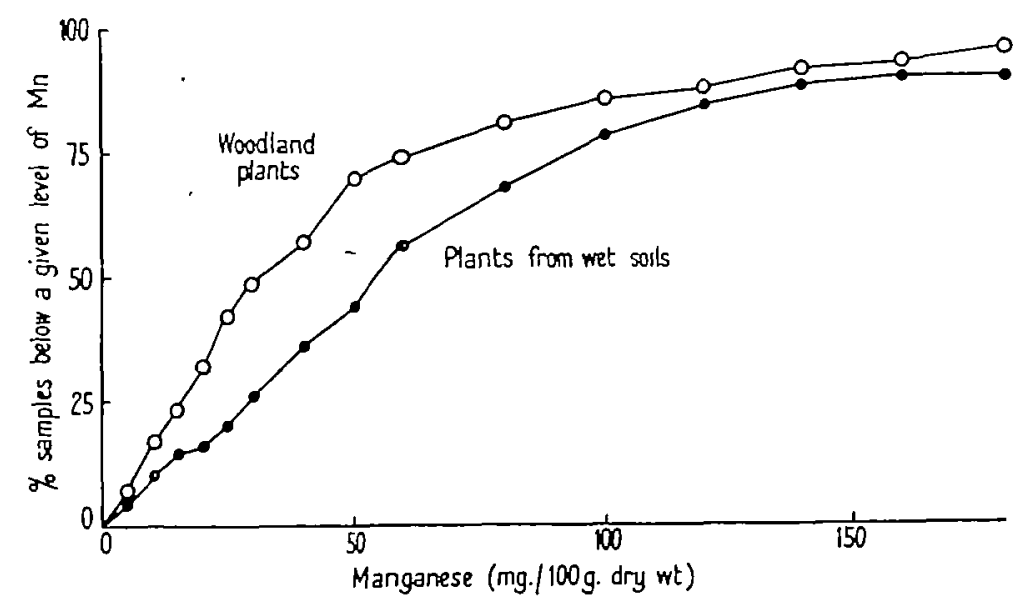

Fig. 6. Manganese in green plants from woodland and waterlogged soils.

As a further point of interest, we may compare by the graphical method the plants of wet soils with those from woodland. This has been done in Figs. 5 and 6 . It might be expected that the plants from the wet soils which are often reducing would take up more iron and manganese than those on the woodland soils with a high redox potential. This is in fact true of manganese. With regard to iron, the curves are similar except at the higher levels, where the very high figures for the aquatic plants bring the line for wet soil plants well below that for woodland. On the wet soils as in woodland, manganese accumulation generally exceeds that of iron on wet soils. 


\section{ACKNOWLEDGEMENTS}

We should like to thank Professor W. H. Pearsall for much helpful advice and criticism, and the Director and staff of the Freshwater Biological Station on Windermere for facilities provided during the collection of the material. The fungi were collected in company with Professor C. T. Ingold, who kindly named them. We should also like to thank Mr. A. Thompson, who identified the Sphagna.

This study was carried out during tenure of scholarships from the Commission for the Royal Exhibition of $185 \mathrm{I}$ (E. G.) and the Department of Scientific and Industrial Research (A. M. M.), to whom are due our best thanks.

\section{Literature Cited}

Bremner, J. M., Heintze, S. G., Mann, P. J. G., and Lres, H., 1946: Metallo-Organic Complexes in the Soil. Nature, clviii. 790-r.

Erkama, J., 1947: Ubber die Rolle von Kupfer und Mangan im Leben der höheren Pflanzen. Helsinki.

Goodalt, D. W., and Gregory, F. G., 1947: Chemical Composition of Plants as an Index to their Nutritional Status. Tech. Comm. 17, Imp. Bur. Hort. and Plant Crops. Aberystwyth.

Gorham, E., I949: Some Chemical Aspects of a Peat Profile. Journ. Ecol., roxvii. 24-7.

Hopkins, E. F., and WaNN, F. B., 1926: Relation of Hydrogen Ion Concentration to Growth of Chlorella and to the Availability of Iron. Bot. Gaz., 1mxxi. 353-76.

IGNatiefF, V., 194I: Determination and Behaviour of Ferrous Iron in Soils. Soil Sci., li. 249-63.

McHargue, J. S., and Roy, W. R., I932: Mineral and Nitrogen Content of the Leaves of Some Forest Trees at Different Times in the Growing Season. Bot. Gaz., xciv. $3^{81} \mathrm{I}-93$.

McMurtrey, J. E. Jr., and Robinson, W. O., 1938: Neglected Soil Constituents that affect Plant and Animal Development. In Soils and Men, Yearbook of Agriculture, U.S.D.A., $807-29$.

MisrA, R. D., r 938 : Edaphic Factors in the Distribution of Aquatic Plants in the English Lake District. Journ. Ecol., xxvi. 4I I-50.

MorTimer, C. H., I94I : The Exchange of Dissolved Substances Between Mud and Water in Lakes. Ibid., kxix. 280-329.

Olsen, C., 1934: The Absorption of Manganese by Plants. Compt. Rend. Trav. Lab. Carlsberg, xx. I-2o.

Pearsall, W. H., 1938: The Soil Complex in Relation to Plant Communities. II. Characteristic Woodland Soils. Journ. Ecol., sarvi. 194-209.

I $938 a$ : The Soil Complex in Relation to Plant Communities. III. Moorlands and Bogs. Ibid., xxvi. 298-315.

Somers, I. I., and ShIVE, J. W., 1942: The Iron-Manganese Relation in Plant Metabolism. Plant Physiol., xvii. 582-602. 


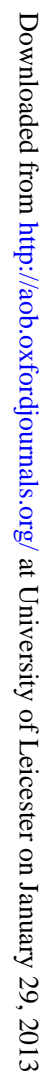

